\title{
Relationships between body condition score, milk yield and milk composition of Sarda goat*
}

\author{
G.M. Vacca ${ }^{1,2}$, V. Carcangiu ${ }^{1}$, M.L. Dettori ${ }^{1}$ and P.P. Bini ${ }^{1}$ \\ ${ }^{1}$ Dipartimento di Biologia Animale, Università degli Studi di Sassari \\ via Vienna, 207100 Sassari, Italia
}

\begin{abstract}
ABSTACT
In order to assess the correlation between body condition score (BCS), milk yield and milk fatty acid (FA) composition, 25 lactating Sarda breed goats were studied. BCS and milk yield were measured monthly, and milk samples for fat, protein, lactose and fatty acid profile analysis were collected. Statistical analysis showed significant correlations between numerous fatty acids and BCS. From these results, it comes out a strong link between milk fatty acid composition and nutritional status of the animal, which could be guided, not only to improve milk productions, but also to characterize its quality.
\end{abstract}

KEY WORDS: goat, BCS, milk composition

\section{INTRODUCTION}

Sarda goat, for amount (about 200.000 heads) and yield, represents the most important Italian goat breed. Spread exclusively in Sardinia, it is reared with traditional technique, and feeding is based on extensive natural grazing, providing supplementary feed rarely. In these conditions, milk yield is remarkably affected by feed sources (grass) availability which depends on climate seasonal changes (Boyazoglu and Morand-Fehr, 2001). Indeed, births occur between November and February and lactations end during the summer months, when the animals have nothing available but some shrub and arboreal vegetation, and body reserves diminish. These variations combine with modifications of milk chemical composition (Vacca et al., 1999), mainly in the lipid fraction, whose metabolism is strongly related with energy balance in mammalian. As regards fatty acids (FA),

\footnotetext{
* Supported by the Amministrazione Provinciale di Nuoro (Italy)

${ }^{2}$ Corresponding author: e-mail: gmvacca@uniss.it
} 
they play an important role in human feeding (Haenlaein, 2004), since they are involved in human health and affect organoleptic properties of animal products. The aim of this study was to assess the links, set up throughout lactation in Sarda goats, between body condition score (BCS) and yield and milk composition.

\section{MATERIAL AND METHODS}

Twenty five lactating goats were examined; they were about 2 years old, and gave birth in January. They were clinically healthy, reared on a natural Mediterranean shrubland, with no supplementary feed. From March to July, monthly, during milking, on each subject BCS according to Santucci et al. (1991) and yield were measured, and a milk sample for analysis was collected. Fat, protein and lactose percentage by infrared assay (Milko-scan, Foss Electric). After extraction of milk fat with ethyl ether-petroleum ether (FIL-IDF 1A 1969) and methylation (Reg. CEE n. 2568/91), fatty acids methyl esters were determined with a Perkin-Elmer Gas Chromatograph Mod. 8310, using a column $30 \mathrm{~m} \times 0,53$ $\mathrm{mm}$. The data obtained, were submitted to correlation and variance analysis, after angular conversion, using a statistical software.

\section{RESULTS}

Mean daily yield, fat, protein and lactose percentage, and body condition score for each observation are given in Table 1 .

Table 1. Milk yield and composition and body condition score, during the experimental period

\begin{tabular}{|c|c|c|c|c|c|c|c|c|c|c|}
\hline & \multicolumn{2}{|c|}{ March } & \multicolumn{2}{|c|}{ April } & \multicolumn{2}{|c|}{ May } & \multicolumn{2}{|c|}{ June } & \multicolumn{2}{|c|}{ July } \\
\hline & mean & s.d. & mean & s.d. & mean & s.d. & mean & s.d. & mean & s.d. \\
\hline Yield, kg/d & $0.53^{\mathrm{B}}$ & 0.18 & $0.76^{\mathrm{C}}$ & 0.35 & $0.79^{\mathrm{C}}$ & 0.33 & $0.51^{\mathrm{B}}$ & 0.17 & $0.42^{\mathrm{A}}$ & 0.13 \\
\hline Fat, $\%$ & $5.58^{\mathrm{b}}$ & 1.20 & $5.11^{\mathrm{a}}$ & 1.11 & $5.29^{\mathrm{a}}$ & 0.99 & $5.60^{\mathrm{b}}$ & 1.08 & $5.79^{b}$ & 1.42 \\
\hline Protein, $\%$ & 4.40 & 0.37 & 4.21 & 0.33 & 4.25 & 0.38 & 3.99 & 0.40 & 4.22 & 0.82 \\
\hline Lactose, \% & $4.96^{\mathrm{E}}$ & 0.27 & $4.73^{\mathrm{D}}$ & 0.29 & $4.59^{\mathrm{C}}$ & 0.20 & $4.31^{\mathrm{B}}$ & 0.22 & $4.03^{\mathrm{A}}$ & 0.34 \\
\hline BCS, points & $2.25^{\mathrm{c}}$ & 0.48 & $2.04^{\mathrm{c}}$ & 0.49 & $1.82^{\mathrm{b}}$ & 0.46 & $1.61^{\mathrm{a}}$ & 0.42 & $1.56^{\mathrm{a}}$ & 0.44 \\
\hline
\end{tabular}

capital letters indicate significant differences for $\mathrm{P}<0.01$; lower letters for $\mathrm{P}<0.05$

The highest milk yields $(\mathrm{P}<0.01)$ were reached in April and June, when the pasture availability was higher. When summer arrived, production levels lowered suddenly. While protein percentage did not show significant variation throughout lactation, fat content presented a trend opposite to yield $(\mathrm{P}<0.05)$, and lactose lowered continuously $(\mathrm{P}<0.01)$. Just like lactose, $\mathrm{BCS}$ variations showed the highest values $(\mathrm{P}<0.05)$ in March $(2.25)$, and lowered gradually up to the end of lactation (1.56). Table 2 indicates $r$ correlation coefficients (and related significance) between BCS, yield and milk chemical composition. 
Table 2. Coefficient $r$ of correlations between BCS and all the other parameters analysed

\begin{tabular}{llllll}
\hline & Milk yield: & 0.094 & & Fat: & -0.162 \\
& protein & 0.099 & & lactose & $0.298^{* * *}$ \\
\hline C 4:0 & butyric & $0.233^{*}$ & C16:1 cis & palmitoleic & $-0.305^{* *}$ \\
C 6:0 & caproic & $0.382^{* * *}$ & C17:0 & heptadecanoic & $-0.429^{* * *}$ \\
C 8:0 & caprylic & $0.351^{* * *}$ & C18:0 & stearic & -0.088 \\
C10:0 & capric & $0.240^{*}$ & C18:1 cis & oleic & $-0.240^{*}$ \\
C12:0 & lauric & $0.244^{*}$ & C18:2 trans & linolelaidic & -0.082 \\
C14:0 & myristic & $-0.238^{*}$ & C18:2 cis & linoleic & $-0.244^{*}$ \\
C14:1 trans & myristelaidic & $-0.208^{*}$ & C18:3 cis & linolenic & $0.302^{* *}$ \\
C14:1 cis & myristoleic & -0.106 & C19:0 & nonadecanoic & -0.101 \\
C15:0 & pentadecanoic & $-0.205^{*}$ & C20:0 & arachidic & -0.129 \\
C16:0 & palmitic & -0.043 & C20:1 & eicosenoic & -0.041 \\
\hline
\end{tabular}

$* * * \mathrm{P}<0.001 ; * * \mathrm{P}<0.01 ; * \mathrm{P}<0.05$

BCS did not show significant correlations with milk yield and milk protein and fat content. Correlation with lactose is highly $(\mathrm{P}<0.001)$ significant. Numerous links between the BCS and the milk FA composition were found, that is a positive correlation with short chain $(\mathrm{C} 4: 0-\mathrm{C} 10: 0)$ and a negative one with middle (C12: 0-C16:1) and long chain (C17:0-C20:1) fatty acids. As regards relationships between productive parameters and milk fatty acidic composition (data not shown), positive correlations between amounts and some satured short chain fatty acids (caproic, caprilic) and negatively to some middle (myristelaidic, palmitoleic, heptadecanoic) and long chain (linolenic, nonadecanoic) fatty acids were shown. Total fat content was correlated exclusively with SFA. Indeed, butirric, lauric and nonadecanoic FA were positively correlated with fat; while palmitic was negatively correlated. Between proteins and fatty acids no significant correlation was registered. Lactose showed, with milk FA composition, the same correlations as with BCS.

\section{DISCUSSION}

The trends of milk yields and FA variations follow the lactation dynamics typical of Sarda goat (Vacca et al., 1999). BCS values showed a trend that was closely related with the pasture seasonal conditions and not to milk yield. This datum does not agree with those related to goats reared in Corsica (Cabiddu et al., 1999). Presumably, the feed available to our goats was not sufficient to reestablish their body reserves, despite the diminished energy demand related to the lessening of production. The links between BCS and milk fatty acid composition are partially explained by the metabolic source of FA. Indeed, part of long chain FAs derives from adipose tissue deposits, while the short chain FAs derive mostly from rumen metabolism (Schmidely and Sauvant, 2001). Moreover, short chain 
FAs are important for their contribution to milk flavour and taste (Bindal and Wadhwa, 1993). In order to keep at good levels the organoleptic characteristics in milk and milk products, the loss of BCS during the final period of lactation should be avoided. Obviously, it is necessary to keep the qualitative characteristics of the natural feed resources available. As regards health aspects, univocal links between BCS and those FA directly involved in human health were not found. Anyway, it is interesting that lauric, myristic and palmitic acids, risk factors for coronary heart disease (CHD), presented low values (4.0, 9.5 and $22.0 \%$, respectively).

\section{CONCLUSIONS}

Our study points out that in extensive breeding conditions the trend of goats' BCS is strongly related to availability of natural feed sources, and it affects milk fatty acid composition. This leads to the possibility to optimize milk quality by means of optimizing animal feeding. It could be useful to improve knowledge of the links between pasture quality and milk composition, as milk traits can also represent an index for their traceability, which is an important goal for supporting and defending local production.

\section{REFERENCES}

Bindal M.P., Wadhwa B.K., 1993. Compositional differences between goat milk fat and that of cows and buffaloes. Small Ruminant Res. 12, 79-88

Boyazoglu J., Morand-Fehr P., 2001. Mediterranean dairy shepp and goat product and their quality. A critical review. Small Ruminant Res. 40, 1-11

Cabiddu A., Branca A., Decandia M., Pes A., Santucci P.M., Masoero F., Calamari L., 1999. Relationship between body condition score, metabolic profile, milk yield and milk composition in goats browsing a Mediterranean shrubland. Livest. Prod. Sci. 61, 267-273

Haenlaein G.F.W., 2004. Goat milk in human nutrition. Small Ruminant Res. 51, 155-163

Santucci P.M., Branca M., Napoleone R., Bouche R., Aumont G., Poisot F., Alexandre G., 1991. Body condition scoring of goats in extensive conditions. In: Morand-Fehr (Editor). Goat Nutrition. Chapter 20, pp. 240-255

Schmidely P., Sauvant D., 2001. Taux butyreau et composition del la matière grasse du lait chez les petits ruminants: effects de l'apport de matièries grasses ou d'aliment concentré. Prod. Anim. $14,337-354$

Vacca G.M., Carcangiu V., Buffa P., Bini P.P., 1999. Variations in the quality of Sarda goats' milk in the first three lactations. Rec. Prog. Anim. Prod. Sci. 1, 484-486 